\title{
A Rare Case of Parvovirus B19 Infection Induced Paroxysmal Cold Hemoglobinuria in an Adult Female
}

\author{
Neenu Kuruvilla ${ }^{1}$, Vishnu Vinay ${ }^{1}$, Rahul Rajendran ${ }^{1}$, $\operatorname{Irshad}$ Ali KM ${ }^{1}$, Sheela Kurian ${ }^{1}$ \\ 1. Internal Medicine, Government Medical College Kottayam, Kottayam, IND
}

Corresponding author: Neenu Kuruvilla, neenukuruvilla17@gmail.com

\begin{abstract}
Paroxysmal cold hemoglobinuria (PCH) is a rare form of autoimmune hemolytic anemia (AIHA). PCH occurs in acute and chronic forms. The main risk factors for PCH include viral infections, vaccination, and syphilis. $\mathrm{PCH}$ presentations are common in the pediatric population. The occurrence of PCH following parvovirus B19 infection in adults is rare. We report a case of a 23-year-old female who presented with giddiness, fatigue, greying of vision, and presyncope for four days, on subsequent evaluation was found to have evidence of hemolysis and bone marrow suppression. Parvoviral intranuclear inclusions were detected in bone marrow biopsy and parvoviral B19 IgM antibody was detected. Donath Landsteiner antibody test was also positive. Hence a diagnosis of PCH secondary to parvovirus B19 infection was made. She was started on pulse dose steroids and intravenous immunoglobulin (IVIG) and showed significant improvement.
\end{abstract}

Categories: Internal Medicine, Pediatrics, Hematology

Keywords: paroxysmal cold hemoglobinuria (pch), parvovirus b19, autoimmune hemolytic anemia (aiha), rare

\section{Introduction}

Paroxysmal cold hemoglobinuria (PCH) is a rare form of autoimmune hemolytic anemia (AIHA), characterized by biphasic, polyclonal IgG autoantibody that binds specifically to the P antigen of RBCs [1]. This binding occurs at a lower temperature leading to complement system activation and red cell lysis at $37^{\circ} \mathrm{C}$. The IgG autoantibody involved is Donath- Landsteiner (DL) antibody [2]. PCH is more common in the pediatric population [3]. PCH can occur in both acute and chronic forms. The important risk factors for acute PCH include viral infections (mumps, measles, chickenpox, Epstein-Barr virus, cytomegalovirus, influenza, parvovirus B19, coxsackievirus A9, and adenovirus) and vaccination (measles) [4,5]. The occurrence of parvovirus B19 infection predisposing to acute $\mathrm{PCH}$ in adults is rare. Here we report such a rare case of parvovirus B19 induced acute $\mathrm{PCH}$.

Review began 10/27/2020 Review ended 11/11/2020 Published 11/22/2020

(c) Copyright 2020

Kuruvilla et al. This is an open access article distributed under the terms of the Creative Commons Attribution License CC-BY 4.0., which permits unrestricted use, distribution, and reproduction in any medium, provided the original author and source are credited.

\section{Case Presentation}

A 23-year-old Indian female, with no significant past medical history and family history, presented to our hospital with giddiness, fatigue, greying of vision, and presyncope for four days. There was no history of fever, chest pain, palpitation, shortness of breath, pedal edema, abdominal pain, vomiting, hematemesis, haematuria or, malena. She denied any history of alcohol intake or substance abuse. Her menstrual cycles were regular with no history of menorrhagia or polymenorrhoea. The patient was on a non-vegetarian diet. On examination, she was conscious and oriented, with a temperature of $37^{\circ} \mathrm{C}$, pulse rate of $114 / \mathrm{min}$, blood pressure of $110 / 60 \mathrm{~mm} \mathrm{Hg}$, respiratory rate of $18 / \mathrm{min}$, and $\mathrm{SpO} 2$ of $96 \%$ in room air. Physical examination showed the presence of pallor in the conjunctiva, nailbed, and palms. Systemic examination was unremarkable except for a systolic flow murmur. Labs at presentation were significant for bicytopenia (Table 1). 


\section{Cureus}

\begin{tabular}{|c|c|c|}
\hline Variable & Measurement & Reference Values \\
\hline Hemoglobin (g/dL) & 6.7 & 12-16 \\
\hline Total leucocyte count $\left(/ \mathrm{mm}^{3}\right)$ & 2400 & $4000-11,000$ \\
\hline Neutrophils (\%) & 36 & $50-70$ \\
\hline Lymphocytes (\%) & 46 & $30-45$ \\
\hline Platelet count $\left(/ \mathrm{mm}^{3}\right)$ & $2,05,000$ & $1,50,000-4,50,000$ \\
\hline $\operatorname{ESR}(\mathrm{mm} / \mathrm{h})$ & 148 & $0-20$ \\
\hline $\operatorname{MCV}\left(\right.$ microm $\left.^{3}\right)$ & 99 & $80-98$ \\
\hline MCHC (g/dL) & 34 & $33-36$ \\
\hline MCH (pg/cell) & 34 & $28-32$ \\
\hline Urea (mg/dL) & 16 & $8-20$ \\
\hline Creatinine (mg/dL) & 0.5 & $0.5-1.1$ \\
\hline Total bilirubin (mg/dL) & 1.3 & $0.3-1.0$ \\
\hline Direct bilirubin (mg/dL) & 0.3 & $0.1-0.3$ \\
\hline ALT (units/L) & 36 & $10-40$ \\
\hline AST (units/L) & 28 & $10-40$ \\
\hline ALP (units/L) & 66 & $30-120$ \\
\hline
\end{tabular}

\section{TABLE 1: Labs at presentation}

MCV: mean corpuscular volume; ESR: erythrocyte sedimentation rate; $\mathrm{MCHC}$ : mean cell hemoglobin concentration; $\mathrm{MCH}$ : mean cell hemoglobin; ALT: alanine transaminase; AST: aspartate transaminase; ALP: alkaline phosphatase

ECG and chest X-ray were normal. ultrasound of abdomen showed no hepatosplenomegaly. On the second day of hospital stay, she collapsed suddenly. On examination, she was tachycardic and hypotensive with a pulse rate of 112/min, and blood pressure of $80 / 60 \mathrm{~mm} \mathrm{Hg}$. Labs showed a rapid decline in hemoglobin and evidence of hemolysis (Table 2). She was transferred to the ICU, transfused with two units of packed red cells, and was started on pulse dosage steroids with intravenous methylprednisolone $1000 \mathrm{mg}$ once daily. There was no history of cold shower or swimming that led to a rapid change in body temperature. 


\section{Cureus}

\begin{tabular}{|l|l|l|}
\hline Variable & Measurement & Reference values \\
\hline Hemoglobin (g/dl) & 2.7 & $12-16$ \\
\hline Total leucocyte count & 3700 & $4000-11,000$ \\
Neutrophils (\%) & 63 & $50-70$ \\
\hline Lymphocyte $(\%)$ & 28 & $30-45$ \\
\hline Platelet count & $2,24,000$ & $1,50,000-4,50,000$ \\
\hline Total bilirubin $(\mathrm{mg} / \mathrm{dL})$ & 2.4 & $0.3-1.0$ \\
\hline Direct bilirubin $(\mathrm{mg} / \mathrm{dL})$ & 0.4 & $0.1-0.3$ \\
\hline Reticulocyte count $(\%)$ & 0.1 & $0.5-1.5$ \\
\hline LDH (units/L) & 696 & $80-225$ \\
\hline TSH (micro Units/mL) & 0.9 & $0.5-4.0$ \\
\hline Serum vitamin B12 (pg/mL) & 400 & $200-800$ \\
\hline Serum folate $(\mathrm{ng} / \mathrm{mL})$ & 12 & $1.8-9.0$ \\
\hline Serum iron $(\mathrm{microg} / \mathrm{dL})$ & 80 & $50-150$ \\
\hline TIBC (microg/dL) & 300 & $250-310$ \\
\hline Transferrin saturation $(\%)$ & 30 & $20-50$ \\
\hline Serum ferritin $(\mathrm{ng} / \mathrm{mL})$ & 100 & $11-307$ \\
\hline ANA-IF & Negative & \\
\hline
\end{tabular}

TABLE 2: Labs on Day 2 showed rapid decline in hemoglobin level, evidence of hemolysis and low reticulocyte count

TB: total bilirubin; DB: direct bilirubin; DCT: direct Coombs test; LDH: lactate dehydrogenase; TSH: thyroid stimulating hormone; TIBC: total iron binding capacity; ANA-IF: antinuclear antibody immunofluorescence

Peripheral smear showed normocytic normochromic anemia and leucopenia with a neutrophilic predominance. In view of severe bicytopenia and low reticulocyte count, bone marrow biopsy was done and revealed evidence of proerythroblasts with parvoviral intranuclear inclusions (Figure 1). Parvovirus B19 IgM was found to be positive. Hence she was initiated on intravenous immunoglobulin (IVIG) and continued for five days. 


\section{Cureus}

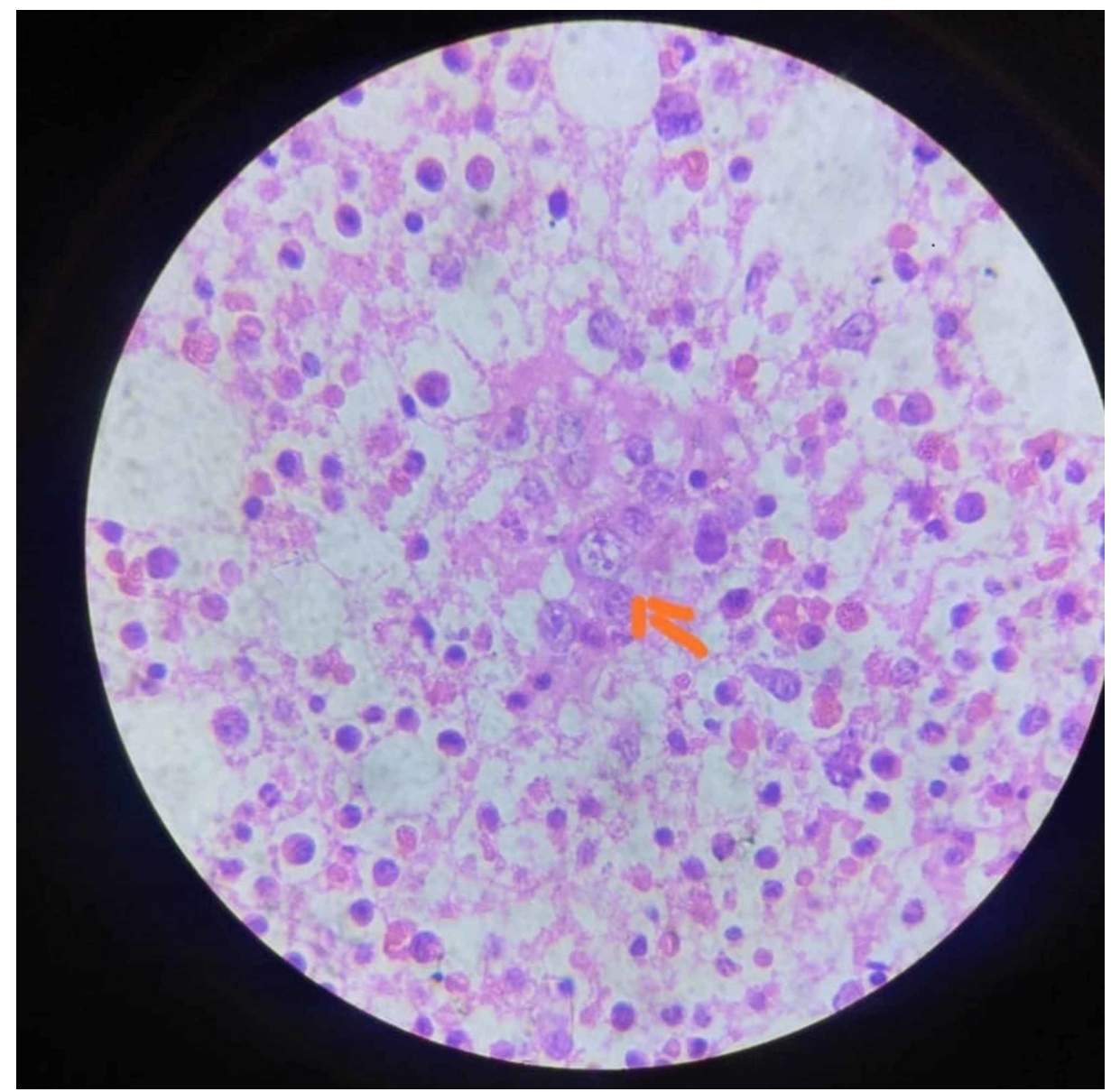

FIGURE 1: Bone marrow biopsy showing parvoviral intranuclear inclusions

Arrow-head shows parvoviral intranuclear inclusion inside the proerythroblast cell.

A hemolytic anemia workup was done to confirm the type of autoimmune hemolytic anemia. Direct Coombs test (DCT) for monospecific and polyspecific IgG/C3d was positive. The thermal amplitude of the antibody was found to be $4+$ at $4^{\circ} \mathrm{C}, 2+$ at $22^{\circ} \mathrm{C}$, and reactive at $37^{\circ} \mathrm{C}$, with evidence of hemolysis. Cold agglutination titer performed in normal saline plain gel card was found to be negative. DL test was done (Figure 2) and showed a positive result (Figure 3). Hence a diagnosis of PCH secondary to parvoviral B19 was made.

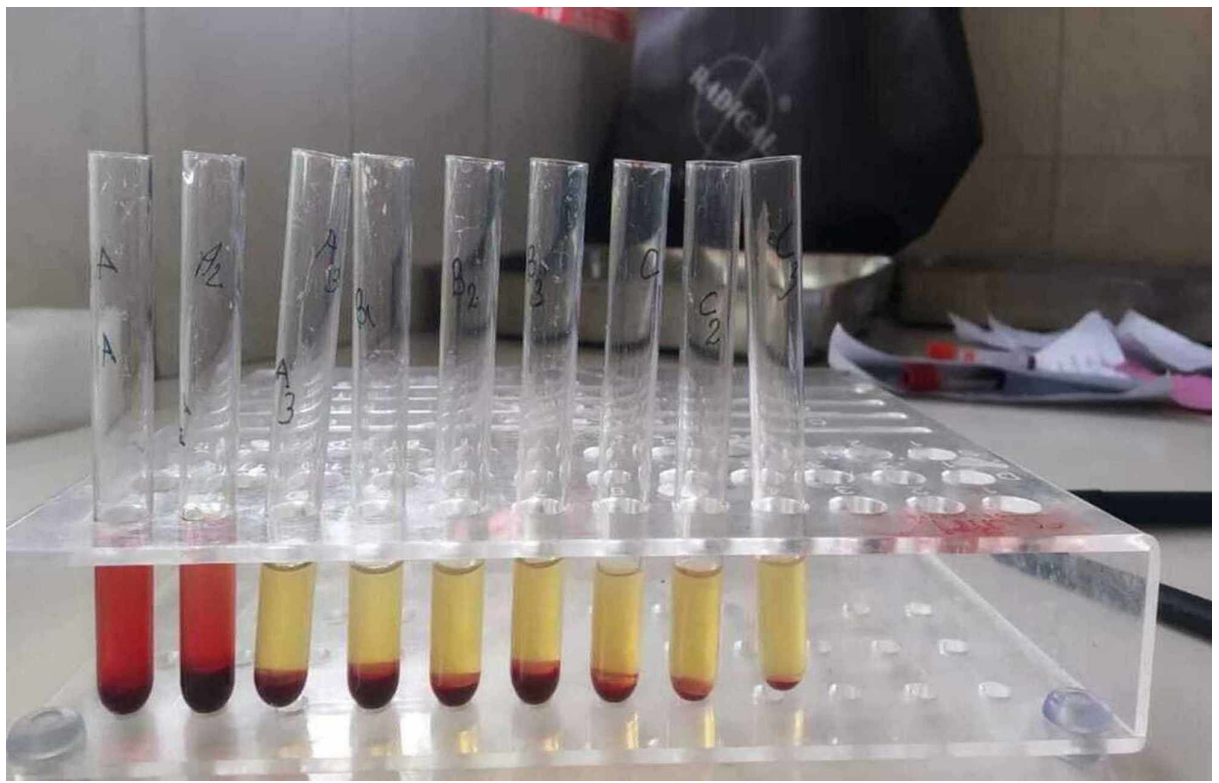




\section{Cureus}

\section{FIGURE 2: Donath Landsteiner test}

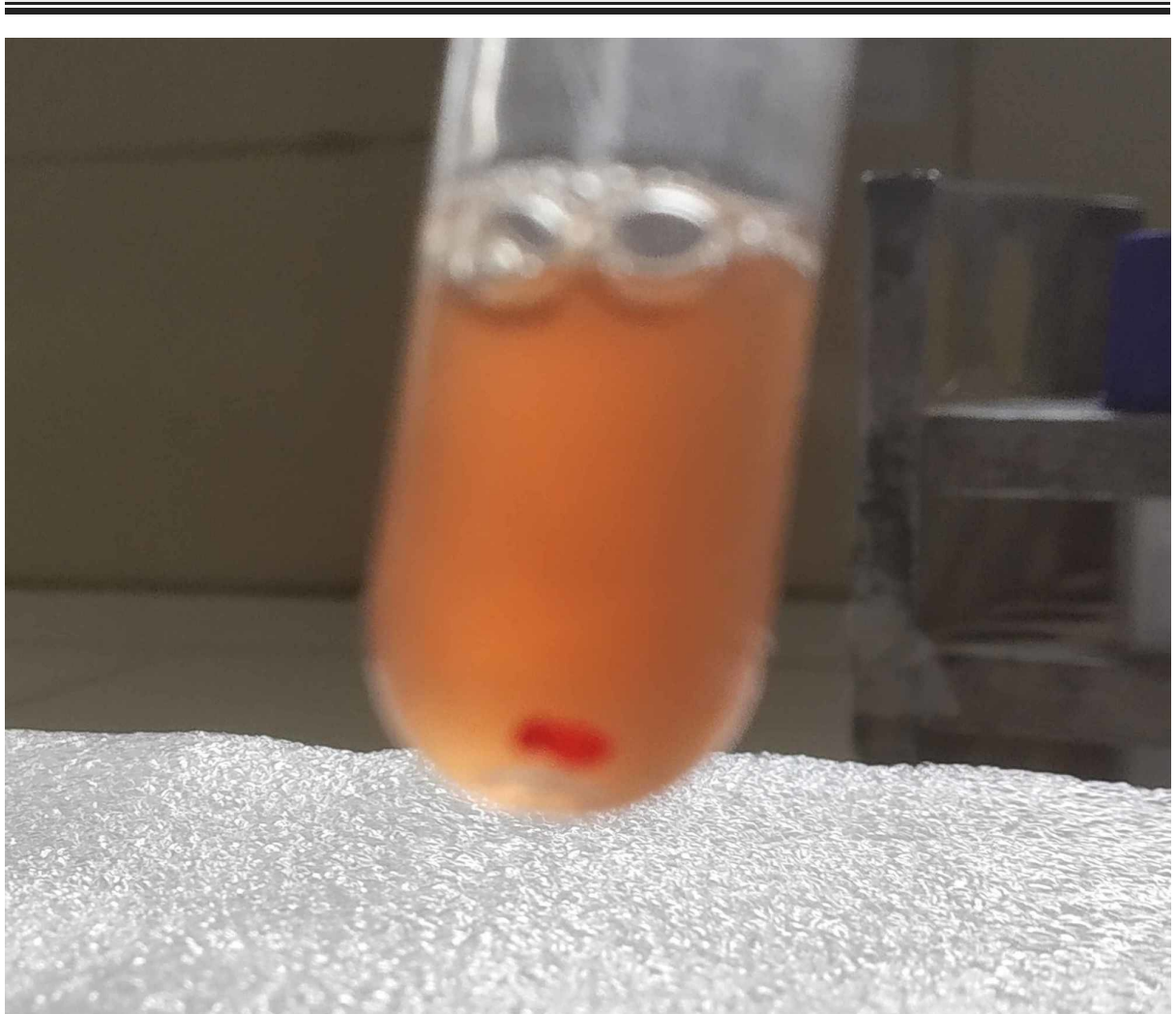

FIGURE 3: Positive Donath Landsteiner test

She was continued on IVIG and steroids. Her general condition improved over the next one week. The total duration of hospital stay was four weeks. She was discharged on a tapering dose of steroids with oral prednisolone $50 \mathrm{mg}$ once daily.

\section{Discussion}

PCH is an AIHA characterized by DL antibody causing red cell lysis [6]. The occurrence of PCH is rare, accounting for less than $1 \%$ of all autoimmune hemolytic anemias [7]. PCH causes complement fixation at low temperatures, subsequently leading to intravascular hemolysis on rewarming. $\mathrm{PCH}$ can present in both acute and chronic forms. When PCH was first identified, it was described as a chronic condition in adults with tertiary syphilis [5]. With the advent of effective treatment for syphilis, the chronic relapsing form of $\mathrm{PCH}$ became rare [8]. Nowadays, the common presentation of $\mathrm{PCH}$ is an acute transient non-recurring illness.

Acute PCH predominantly occurs in the pediatric population with a recent history of viral illnesses or following immunization [9]. The incidence in pediatric groups is $0.001 / 100000$ per year in boys and $0.0005 / 100000$ per year in girls $[10,11]$. The mean age of onset is 3.8 years [8]. Certain viruses have been implicated in precipitating episodes of PCH in children, including measles, mumps, varicella, cytomegalovirus, Epstein - Barr virus, influenza virus, parvovirus B19, coxsackie, and adenovirus [12]. The mechanism of how an infectious agent induces PCH is poorly understood. One proposed theory suggests that viruses alter the glycoproteins on the erythrocyte membrane which further stimulates autoantibody formation [4]. Another theory points that molecular mimicry between self-antigens and foreign antigens leads to the production of cross-reactive antibodies [4].

Typical clinical features include fever, chills, abdominal pain, and hemoglobinuria on exposure to cold. Hemoglobinuria can persist for several months despite the resolution of intravascular hemolysis. Physical examination may show fever, pallor, icterus, and abdominal tenderness [13]. Laboratory findings include features of red blood cell lysis like indirect hyperbilirubinemia, low haptoglobin, decreased complement, elevated LDH, reticulocytosis, and hemoglobinuria. Hemosiderinuria is also characteristic but usually develops three to four days after the onset of hemolysis. The pathognomonic finding is erythrophagocytosis by neutrophils in peripheral blood smear [5]. The diagnosis of PCH is confirmed by the presence of 
DL antibodies [14]. The DL antibody fixes the first two components of the complement cascade and dissociates upon rewarming. This results in complement-mediated intravascular hemolysis. The original assay for the DL test used patient serum along with test RBCs and a pooled human serum. These are incubated at $4^{\circ} \mathrm{C}$ to allow the antibody to bind and subsequently fix the complements. This is then transferred to $37^{\circ} \mathrm{C}$ to allow for the latter components of complement to be activated and leading to hemolysis. As a control, hemolysis does not occur if the reaction mixture is maintained continuously at $37^{\circ} \mathrm{C}$ because the $\mathrm{DL}$ antibodies require cold temperature for RBC sensitization. To demonstrate the $\mathrm{P}$ antigen specificity of DL antibody, $\mathrm{ABO}$-compatible, $\mathrm{P}$ antigen-negative $\mathrm{RBCs}$ may be used as a negative control.

Because of the biphasic nature, the direct antiglobulin test (DAT) is negative for IgG and positive for anti-C3 [4]. Cold agglutinin disease is one of the main differential diagnoses. But it can be distinguished from PCH by a negative DL test, peripheral blood smear showing RBC agglutination, and a positive serum IgM.

The treatment of an acute episode of PCH is generally supportive, which includes analgesics and avoidance of cold exposure. Individuals with severe hemolysis may require adequate hydration, blood transfusions, and glucocorticoids [15]. Blood transfusions must be administered using a blood warmer to prevent the binding of autoantibody to the transfused cells [16]. For patients with on-going hemolysis, more potent immunosuppressive therapies, and anti-complement therapies like treatment with rituximab, cyclophosphamide or azathioprine may be helpful [17]. Plasmapheresis can also be used to lower the antibody titer [18].

\section{Conclusions}

PCH in adults, with parvovirus B19 precipitating the same, is rare. It can occur in acute and chronic forms. Acute forms are more common in the pediatric population, with viral infections and vaccinations being the major etiologies. Chronic forms are rare in the modern era due to effective treatment for syphilis. The diagnosis of PCH is confirmed by the presence of DL antibodies. PCH is treated supportively, with analgesics and avoidance of cold exposure.

\section{Additional Information}

\section{Disclosures}

Human subjects: Consent was obtained by all participants in this study. Conflicts of interest: In compliance with the ICMJE uniform disclosure form, all authors declare the following: Payment/services info: All authors have declared that no financial support was received from any organization for the submitted work. Financial relationships: All authors have declared that they have no financial relationships at present or within the previous three years with any organizations that might have an interest in the submitted work. Other relationships: All authors have declared that there are no other relationships or activities that could appear to have influenced the submitted work.

\section{References}

1. Levine P, Celano M. J, Falkowski F: The specificity of the antibody in paroxysmal cold hemoglobinuria (P.C.H.). Ann N Y Acad Sci. 1965, 124:456-461. 10.1111/j.1749-6632.1965.tb18978.x

2. Sokol RJ, Booker DJ, Stamps R: Paroxysmal cold hemoglobinuria and the elusive Donath-Landsteiner antibody. Immunohematology. 1998, 14:109-112.

3. Barcellini W: New insights in the pathogenesis of autoimmune hemolytic anemia . Transfus Med Hemother. 2015, 42:287-293. 10.1159/000439002

4. Leibrandt R, Angelino K, Vizel-Schwartz M, Shapira I: Paroxysmal cold hemoglobinuria in an adult with respiratory syncytial virus. Case Rep Hematol. 2018, 2018: 10.1155/2018/7586719

5. Bunch C, Schwartz FC, Bird GW: Paroxysmal cold haemoglobinuria following measles immunization. Arch Dis Child. 1972, 47:299-300. 10.1136/adc.47.252.299

6. Fukuda M, Furuya H, Notsu K, Takagi C, Suyama Y, Ishikura H, Kato Y: Adult type of idiopathic paroxysmal cold hemoglobinuria. [Article in Japanese]. J Clin Hematol. 1991, 32:1498-1502.

7. Barcellini W: Immune hemolysis: diagnosis and treatment recommendations. Semin Hematol. 2015, 52:304312. 10.1053/j.seminhematol.2015.05.001

8. Heddle NM: Acute paroxysmal cold hemoglobinuria. Transfus Med Rev. 1989, 3:219-229. 10.1016/S08877963(89)70082-1

9. Gunawardena D, Velu M, Senaviratne SN: Case report on a child with paroxysmal cold haemoglobinuria . Indian J Hematol Blood Transfus. 2012, 28:112-113. 10.1007/s12288-011-0094-y

10. Papalia MA, Schwarer AP: Paroxysmal cold haemoglobinuria in an adult with chicken pox . Br J Haematol. 2000, 109:328-329. 10.1046/j.1365-2141.2000.02010.x

11. Sokol RJ, Hewitt S, Stamps BK: Haemolysis associated with donath-landsteiner antibodies'. Acta Haematol. 1982, 68:268-277. 10.1159/000206992

12. Sanford KW, Roseff SD: Detection and significance of Donath-Landsteiner antibodies in a 5-year-old female presenting with hemolytic anemia. Lab Med. 2010, 41:209-212. 10.1309/LM1E9Z2QZEREPAI

13. Slemp SN, Davisson SM, Slaytenet J, Cipkala DA, Waxman DA: Two case studies and a review of paroxysmal cold hemoglobinuria. Lab Med. 2014, 45:253-258. 10.1309/LMWD51B2KIFSBLBJ

14. Bhatt R, Calvo L, Raju G, Podrumar A: Case of Donath-Landsteiner haemolytic anaemia in an adult female . BMJ Case Rep. 2018, 2018:10.1136/bcr-2018-226475 


\section{Cureus}

15. Jaime-Pérez JC, Rodríguez-Martínez M, Gómez-de-León A, Tarín-Arzaga L, Gómez-Almaguer D: Current approaches for the treatment of autoimmune hemolytic anemia. Arch Immunol Ther Exp. 2013, 61:385-395. 10.1007/s00005-013-0232-3

16. Barros MMO, Blajchman MA, Bordin JO: Warm autoimmune hemolytic anemia: recent progress in understanding the immunobiology and the treatment. Transfus Med Rev. 2010, 24:195-210. 10.1016/j.tmrv.2010.03.002

17. Koppel A, Lim S, Osby M, Garratty G, Goldfinger D: Rituximab as successful therapy in a patient with refractory paroxysmal cold hemoglobinuria. Transfusion. 2007, 47:1902-1904. 10.1111/j.1537 2995.2007.01414.x

18. Andersen E, Skov F, Hippe E: A case of cold haemoglobinuria with later sarcoidosis. Treatment with plasmapheresis and immunosuppressiva. Scand J Haematol. 1980, 24:47-50. 10.1111/j.16000609.1980.tb01316.x 